NASȦ Technical Memorandum 88861

\title{
Probabilistic Structural Analysis Methods for Space Propulsion System Components
}

(NASA-TM-8886 1) EFOBAEIL ISTIC STRUCTURAL ANALYSIS METAODS FCR SPACE ERCECLSION SYSTEM

Christos C. Chamis

Lewis Research Center

Cleveland, Ohio

Prepared for the 3rd Space System Technology Conference sponsored by the American Institute of Aeronautics and Astronautics San Diego, California, June 9-12, 1986 
PROBABILISTIC STRUCTURAL ANALYSIS METHODS FOR SPACE PROULSION

SYSTEM COMPONENTS

Christos C. Chamis

National Aeronautics and Space Administration

Lewis Research Center

Cleveland, Ohio 44135

\begin{abstract}
SUMMARY
NASA Lewis Research Center is currently developing probabilistic structural analysis methodology for select Space Shuttle Main Engine (SSME) components. This methodology consists of the following program elements:

(1) composite load spectra, (2) probabilistic structural analys is methods, (3) probabilistic finite element theory - new variational principles, and (4) probabilistic structural analysis application. The methodology has led to significant technical progress in several important aspects of probabilistic structural analysis. The program and significant accomplishments to date are summartzed in this paper.
\end{abstract}

\title{
INTRODUCTION
}

It is becoming increasingly evident that deterministic structural analysis methods will not be sufficient to properly design critical structural components for upgraded Space Shuttle Main Engines (SSME). Structural components in the SSME are subjected to a variety of complex, severe cyclic and transient loading conditions including high temperatures and high temperature gradients. Most of these are quantifiable only as best engineering estimates. These complex loading conditions subject the material to coupled nonlinear behavior which depends on stress, temperature, and time. Coupled nonlinear material behavior is nonuniform, is very difficult to determine experimentally, and perhaps impossible to describe deterministically. In addition critical SSME structural components are relatively small. Fabrication tolerances on these components, which in essence are small thickness variations, can have significant effects on the component structural response. Fabrication tolerances by their very nature are statistical. Furthermore the attachment of the components to the structural system generally differs by some indeterminant degree from that which was assumed for designing the component. In summary, all four fundamental aspects - (1) loading conditions, (2) material behavior, (3) geometric configuration, and (4) supports - on which structural analyses are based, are of a statistical nature. One direct way to formaliy account for all these statistical aspects is to develop probabilistic structural analysis methods where all participating variables are described by appropriate probabilistic functions.

NASA Lewis Research Center is currently developing probabilistic structural analysis methods for select SSME structural components. Briefly, the deterministic, three-dimensional. inelastic analys is methodology developed under the Hot Section Technology ((HOST) and R\&T Base programs) is being augmented to accommodate the complex probabilistic loading spectra, the thermoviscoplastic material behavior, and the material degradation associated with the environment of space propulsion system structural components representative 
of the SSME, such as turbine blades, transfer duct, and liquid-oxygen posts (fig. 1 ).

The development of probabilistic structural analysis methodology consists of the following program elements: (1) composite load spectra, (2) probabilistic structural analysis methods, (3) probabilistic finite element theory new variational principles, and (4) probabilistic structural analys is application. The development of the probabilistic structural analysis methodology is a joint effort of NASA Lewis in-house research, contracts, and grants. The objective of this paper is to describe briefly the program and to highlight significant accomplishments to date.

\section{PROGRAM DESCRIPTION/PARTICIPANTS}

The major part of the program consists of two multiyear contracts. One contract (NASA contract NAS3-24382) is for the development of composite load spectra. The prime contractor is Rocketdyne, a division of Rockwell International Corporation, with Battelle Columbus Laboratory, as a subcontractor. Rocketdyne is responsible for the overall program and integrated computer codes while Battelle is responsible for developing probabilistic models. The other contract (NASA contract NAS3-24389) is for the development of probabilistic structural analysis methods. The prime contractor is Southwest Research Institute with several subcontractors. The initial participants on this contract are: Southwest Research Institute - project management and solution strategies development; MARC Analysis Research Corporation - code development for probabilistic finite element methods; Rocketdyne Division, Rockwell International Corp. - Space Shuttle Main Engine (SSME) design and hardware experience; Prof. Paul Wirsching (University of Arizona) - probabilistic and reliability methods; Prof. Gautam Dasgupta (Columbia University) - stochastic finite elements; and Prof. Satya Atluri (Georgia Tech) - advanced material constitutive models. The remaining part of the program consists of one grant (NAG 3-535) with Northwestern University and the in-house effort which is supported by support service contract personnel from Sverdrup Technology Incorporated under NASA contract NAS3-24105. The program is summarized in figure 2.

The research activities have led to significant technical progress in several important aspects of probabilistic structural analysis. Technical progress is reported in monthiy reports and oral contract progress reviews. In addition, progress was reported at the Structural Integrity and Durability of Reusable Space Propulsion Systems Conference held at NASA Lewis Research Center on June 4-5, 1985 (refs. 1 to 7). Furthermore, progress was reported in the ASME Winter Annual Meeting in Mtami, Florida, November 1985, where a whole session was devoted to this subject (refs. 8 to 12). The information presented in this paper summarizes progresses reported in all these sources.

\section{COMPOSITE LOAD SPECTRA}

The main thrust of the composite load spectra (CLS) contractual effort is to develop generic probabilistic models for the various individual loads, their probable combinations for the select SSME components and attendant computer codes (refs. 2 and 3 ). The tasks of the contractural effort are summarized in figure 3 . The type of avallable information to aid in the development of the generic probabilistic models is summarized in table 1 for the high pressure 
fue 1 turbopumps (HPFTP) blade. Limited but typical measured data for comparable information is shown in figure 4 . The logic chart for analyzing and reducing test or flight measured data is shown in figure 5 . The types of individual loads identified to date for four SSME components are summarized in table 2 where the source for obtaining data for these individual loads is also shown. As can be seen in this table each component is subjected to combinations at least nine individual load conditions.

The generic probabilistic models for each of the individual loads consist of 4 parts: (1) a steady state load, (2) a periodic load, (3) a random load, and (4) a local spike. Each of these parts is formally described with a mean and a variance or a standard deviation. The shape of each part is determined using three different probabilistic distributions. Three probabilistic methods are also used for the phasing of these four parts into a single probabilistic load model. It is believed at this time that the four parts for each load condition will be sufficient to realistically represent present and anticipated individual loading conditions. The shape of each of the four parts is described parametrically with undetermined coefficients. These coefficients are selected by combinations of known data, computationally simulated data, and information provided by experts.

The generic model for the time phasing (or combination) of the individual loads into the composite load spectra is also formulated using three probabilistic methods. The formulation is based on combinations of iimited known/ anticipated data (of the type shown in fig. 4 for example), information estimated by experts, and largely on the probabilistic synthes is of probabilistically occurring events. The rationale for using varlous levels of progressive sophistication of probabilistic models for both the individual loads and the composite load spectra is to "balance" the uncertainties associated with the various estimates used in the formulations of these models. The models are then validated/adapted by using appropriate structural analyses, and assessing the resulting structural responses. The selection of the structural analyses to be used is obtained from point design information which is either known or computationaliy simulated by using expert opinions. Structural analyses of these types are also used to determine the reliability and the respective level of confidence for the composite load spectra to be applied to a specific component.

There are four important considerations in the development of each mode1: (1) the ability of the model to handle nonstandard distributional forms, (2) the treatment of nonstationary processes, (3) the handing of physical dependencles in the model, and (4) the ability of the method to operate efficiently so that it will be able to be included in an expert system computer code. The structure for each probabilistic generic model has a distribution fitting routine for the individual loads with a barrier crossing method, Discrete Probability Distribution (DPD) method, and a Monte Carlo method for the combined and composite load models. A transformation method for changing nonstationary load processes into stationary processes is also included in the model so that the barrier crossing techniques can be used for a broader spectrum of problems. Because these models are based on the probability density function representing the frequency of the various load levels occurring, all forms of load shape curves can be handled including nominal (rectangular pulse), periodic, periodic over nominal, and random over nominal. The case of spike (transient) loads occurring is handled with a simulation method, or, if 
appropriate, the barrier crossing method. A typical individual load record determined using this approach is shown in figure 6 .

\section{EXPERT SYSTEM COMPUTER CODE}

The integrated computer code for the composite load spectra is an executively driven modular software system that will incorporate the various individual and composite load spectra models. This code is configured as an "expert system". Modules in this code will contain the various probabilistic models with data dependent coefficients and/or functions and with the increasing levels of sophistication with respect to prediction reliability and confidence level. Associated with these models are guidelines to select the coefficients and functions in the generic models to achieve a specified prediction requirement. The potential complexity and the expertise inherent in generic models to construct specific load spectra, justifies embedding these models in an integrated software system configured as an expert system that can advise users in the employment of the generic load models.

The code is being developed in four incremental versions. Each subsequent version will add a new engine component, additional load types and more sophistication to the probabilistic load definition and decision making process. The technical core of the final integrated system will be an interactive expert system that will: (1) construct specific load spectra models based on user supplied descriptions of the component and the load environment; (2) incorporate the probabilistic models so as to enable a dialogue between the system and the user which will help the user select the best model parameters for his problem; and (3) be able to describe the process of constructing a specific load spectra model, including decisions made by the expert system and the rationale for those decisions. The key features of the code are summarized in figure 7 .

The expert system is being configured so that specific simulated load spectra models are built by accessing a knowledge base of facts and rules. The knowledge base contains a module of decision-making data (facts) and a module of rules and decision criteria (rules) for constructing the load spectra mode1. All numerical results needed to construct the specific load spectra model will be computed or retrieved automatically by the expert system. The knowledge base and the inference mechanisms needed to search the knowledge base will be developed as part of this project. They will be strongly dependent upon the probabilistic generic load spectra models and engine component loading. A schematic of the structure of the expert system is shown in figure 8.

The expert system is being constructed to easily accommodate additions and deletions to the knowledge base. This allows the expert system to "get smarter" and to adapt to new information, both in the test and validation stage of each code version and in the expansion of the expert system to incorporate future models in the later versions of the code. The expert system is interactive to allow the system to query and guide the user as to the system operation (e.g., required user's input). The knowledge base and inference mechanism is being designed to minimize redundant data requests from the system to the user. The software system is modular in conformance with modern programming practice. The source program is written in the FORTRAN language in order to assure a stand alone and portable code. 


\section{PROBABILISTIC STRUCTURAL ANALYSIS METHODS (PSAM)}

The focus of the PSAM contractual effort (refs. 4, 5, and 9 to 21) is to develop analysis methods and computer programs for predicting the probabilistic response of critical structural components for current and future space propulsion systems. This methodology will play a central role in establishing increased system performance and durability. The initial activity of PSAM is the development of a probabilistic finite element code for the probabilistic structural analysis of the select SSME components. The computer code being developed is NESSUS (Numerical Evaluation of Stochastic Structures Under Stress). It is based on the integration of existing technologies (fig. 9).

The development of the NESSUS code is scheduled to take 3 years. First year efforts involve the formulation of the probabilistic analysis strategy and the development of a probabilistic linear analysis code. The ultimate goal of the 3-year program is the development of a finite element code capable of performing nonlinear dynamic analysis of structures having stochastic material properties, geometry, and boundary conditions and subjected to random loading (fig. 10).

Three levels of sophistication are pursued for the stochastic description of the structural problem namely:

Level 1: Homogeneous random varlable for stiffness, mass, damping, and external loading

Leve 1 2: Stochastic characterization of variables at the element level, with specified interelement correlations

Leve 1 3: Stochastic interpolation of variables within a finite element

Two alternative probabilistic analys is methods are being developed, allowing for all three levels of modeling sophistication. These two methods are:

(1) A probability integration method, providing a direct estimate of the reliability of the structural configuration under study.

(2) A simulation method, providing the means to verify the results obtained with method 1.

The finite element library of NESSUS is shown in figure 11 together with the perturbation variables and the processors. A demonstration problem of the NESSUS status is brlefly described below to illustrate PSAM-type of computational simulation. The problem chosen is a curved shell representing a.HPFTP blade. The finite element model for this shell-blade consists of 48 bilinear shell elements, 63 nodes, and $378^{\circ}$ of freedom. The shell is loaded with random pressure and temperature fields. These fields have a constant mean value over the surface but are spatially correlated through an exponential decay function. For pressure, the correlation was assumed strong in the spanwise and weak in the chordwise directions. The opposite was assumed true for the temperature field.

The other random variables were shell thickness and stiffness at the base. The thickness variability could come from manufacturing processes, while base 
stiffness variations may arise from normal assembly procedures. Proper definition of boundary conditions as reflected in the base stiffness may not be we 11 defined and could be a major source of uncertainty in a structural analysis. This would be especially true for an elgenvalue analysis where natural frequency is the critical response variable.

Randomness was included in the elastic modulus and coefficient of thermal expansion of the material by assuming they were deterministic functions of temperature. For the strength analysis, material yield strength was also assumed to be stochastic. The distributions, their means and coefficients of variation for the random variables, were not taken to represent a particular SSME material, structure, or operating environment. They were selected as being representative of what might be expected. The higher coefficients of variations for the base stiffness factor and the pressure reflect the greater uncertainty these random variables are expected to have in actual service. For this analysis the only limitation on the choice of distributions is that the temperature and pressure fields were taken to be normal.

The NESSUS code was executed for a number of preselected perturbations about the deterministic state. In this example, the deterministic solution was defined at the mean value of the random variables. A total of 40 perturbed solutions were obtained at \pm 7.5 and \pm 3.0 standard deviations of the 11 random variables required for the combined stress performance function (Von Mises criterion). The use of the modified Newton-Raphson iteration method allowed for efficient computation of the perturbed solutions without repeated reformulation and resolution of the matrix equations. Clearly the number of perturbations required to construct a performance function depend on the number. of random variables; consequently, for computational efficiency, only the significant varlables should be retained in the analysis. The results obtained for excedence of Von Mises type stress are summarized in figure 12 (lower right) where the blade-shell finite element model, the NESSUS code flow chart and the input random variables are also shown.

\section{VARIATIONAL THEORY FOR PROBABILISTIC FINITE ELEMENTS}

A small but important part of the probabilistic structural analys is methodology is the development of variational principles for formulating probabilistic finite elements. This part is considered to be fundamental and is pursued under a grant (refs. 6 to 8 ) which focuses on embedding the probabilistic aspects in a variational formulation. A variational approach to probabilistic finite elements enables it to be incorporated within standard finite element methodologies. Therefore, once the procedures have been developed, they could easily be adapted to existing general purpose programs. The variational basis for these methods enables them to be adapted to a wide variety of structural elements and to provide a consistent basis for incorporating probabilistic features in many aspects of the structural problem: (1) displacements, (2) boundary conditions, (3) body forces resulting from acceleration. loads and, (4) any other features that cannot be clearly established. For example, the well known dilemma as to whether a shell is clamped or simplysupported at a boundary, could also be treated more rationally by using a probabilistic distribution for this boundary condition. Relevant progress of this research effort is summarized below. 
A methodology has been completed which can embed the probabilistic distribution of the constitutive properties and loads (1.e., material uncertainties and load uncertainties) with a finite element variational approach. The corresponding probabilistic distribution of the elemental nodal forces is assembled into a description of the probabilistic distribution of the nodal forces for the complete model. The appropriate mean structural response due to these uncertainties is then determined efficiently. The basic concept of this approach is to incorporate the probabilistic distributions, as reflected in the variance, of the material properties and the loading conditions to obtain the corresponding variances in the elemental nodal forces of the finite element model. On the basis of the variance in the elemental nodal forces, the variance in the final solution is determined in the usual deterministic solution procedures.

Efficient numerical algorithms were developed for obtaining the probabilistic sensitivity element matrices which reflect the effects of randomness on response variables such as displacements, stresses, etc. The randomness is due to the preassigned probabilistic descriptions of the materlal properties and loads.

A pilot computer code was completed. Solutions obtained using this code have been compared to the Monte Carlo methods and the Hermite Gauss Quadrature integration schemes. The cost of the new method is substantially lower. This was demonstrated with a ten-bar probabilistic nonlinear system where the random variables are the yield stresses. Exploitation of this characteristic in any probabilistic analysis may offer significant savings and warrant further investigation. A flow chart of the pllot computer code is shown in figure 13 together with some representative results.

\section{PROBABILISTIC STRUCTURAL ANALYSIS OF SSME TURBOPUMP BLADES}

A probabilistic study has been initiated in-house at NASA Lewis Research Center (ref. 7). The first objective of this study is to evaluate the geometric and material properties tolerances on the structural response of turbopump blades. During this study, a number of important probabilistic variables have been identiffed which are considered to affect the structural response of the blade. In addition, a methodology has been developed to statistically quantify the influence of these probabilistic variables in an optimized way. The identified variables include random geometric and material properties perturbations, different loadings and a probabilistic combination of these loadings. Influences of these probabilistic variables are quantified by evaluating the blade structural response. The structural response variables include natural frequencies, maximum stress at the root, stage weight and tip displacements. Geometric and material perturbations have been conducted for an SSME blade using a special purpose code based on finite element analysis. The geometric perturbations which simulate the natural perturbations under operating and/or fabrication conditions, are generated by randomly perturbing the $x, y$, and $z$ coordinates of all the nodes of the finite element mesh. The material perturbations were generated by randomly perturbing the material properties of all finite elements. These perturbations represent in part material variation resulting from the fabrication process, and/or any other local irregularities. 
Probabilistic models have been developed to predict the structural response by perturbating means and variances. Since means are not significant, probabilistic models based only on the significant varlances have also been developed. In addition, probability distributions for the structural response have been developed. These distributions provide an assessment of variation in the structural response for selected geometric and material properties perturbations. These provide an estimate of the probability of getting a certain response for a given input. Some representative results are shown in figure 14 . Statistical tests and methods were used to check the developed mode 75 . These tests indicated that the developed models are good fits. T-tests were used to identify the significant variances of perturbations. F-tests, plots, and autocorrelations of residuals were used to check the goodness-of-fit tests.

\section{SUMMARY}

NASA Lewis Research Center is currently developing probabilistic structural analysis methods for select SSME structural components. Briefly, the development consists of the following program elements: (1) composite load spectra, (2) probabilistic structural analysis methods, (3) probabilistic finite element theory - new variational principles, and (4) probabilistic structural analysis application. The development of the probabilistic structural analysis methodology is a joint effort of NASA Lewis in-house research, contract, and grants. The research activities have led to significant technical progress in several important aspects of probabilistic structural analysis. The significant technical accomplishments to date demonstrate that structural analyses can be formulated using probabilistic methods where all the participating structuralcomponent-descriptor parameters and variables, and loading conditions are defined probabilistically. An early version of a structural analysis computer code (NESSUS) based on probabilistic finite elements has been completed and is currently used to analyze high pressure turbopump blades. Also the individual loads and composite load spectra can be probabilistically simulated using probabilistic methods with progressive levels of sophistication, limited avallable data, expert opinion, and an expert system driven computer code.

\section{REFERENCES}

1. Chamis, C.C., "Overview of Structural Response: Probabilistic Structural Analysis," Structural Integrity and Durability of Reusable Space Propulsion Systems, NASA CP-2381, 1985, pp. 63-66.

2 Newe 11, J.F., "Composite Loads Spectra for Select Space Propulsion Structural Components," Structural Integrity and Durability of Reusable Space Propulsion Systems, NASA CP-2381, 1985, pp. 67-75.

3. Kurth, R., "Composite Loads Spectra for Select Space Propulsion Structural Components: Probabilistic Load Model Development," Structural Integrity and Durability of Reusable Space Propulsion Systems, NASA CP-2381, 1985, pp. 77-83.

4. Burnside, O.H., "Probabilistic Structural Analys is Theory Development," Structural Integrity and Durability of Reusable Space Propulsion Systems, NASA CP-2381, 1985, PD. 85-92. 
5. Nagtegaa 1, J., "Probabilistic Finite Element Development," Structural Integrity and Durability of Reusable Space Propulston Systems, NASA CP-2381, 1985, pp. 93-98.

6. Belytschko, T., and Liu, W.K., "Probabilistic Finite Element: Variational Theory," Structural Integrity and Durability of Reusable Space Propulsion Systems, NASA CP-2381, 1985, Pp. 99-107.

7. Nagpal, V.K., "Probabilistic Structural Analysis of SSME Turbopump Blades Probabilistic Geometry Effects," Structural Integrity and Durability of Reusable Space Propulston Systems, NASA CP-2381, 1985, pp. 109-115.

8. Liu, W.K., Belytschko, T., and Mani, A., "Probabilistic Finite Element for Transient Analys is in Nonilinear Continue," Advances in Aerospace Structural Analysis, edited by O.H. Burnside and C.H. Parr, ASME, New York, 1985, Pp. 9-24.

9. Burnside, O.H., "Probabilistic Structural Analysis for Space Propulsion System Components." Advances in Aerospace Structural Analys is, edited by 0.H. Burnside and C.H. Parr, ASME, New York, 1985, pp. 87-102.

10. Wirsching, P.H., and Wu, Y.T. "Advanced Reliabllity Methods for Structural Evaluation," Advances in Aerospace Structural Analysis, edited by 0.H. Burnside and C.H. Parr, ASME, New York, 1985, pp. 75-85.

11. Wu, Y.T., "Demonstration of a New, Fast Probability Integration Method for Reliability Analysis," Advances in Aerospace Structural Analysis, edited by 0.H. Burnside and C.H. Parr, ASME, New York, 1985, Pp. 63-73.

12. Dias, J.B. and Nagtegaal, J.C., "Efficient Algorithms for Use in Probabilistic Finite Element Analysis," Advances in Aerospace Structural Analysts, edited by O.H. Burnside and C.H. Parr, ASME, New York, 1985, pp. 37-50. 
TABLE 1. - INDIVIDUAL LOAD SUMMARY

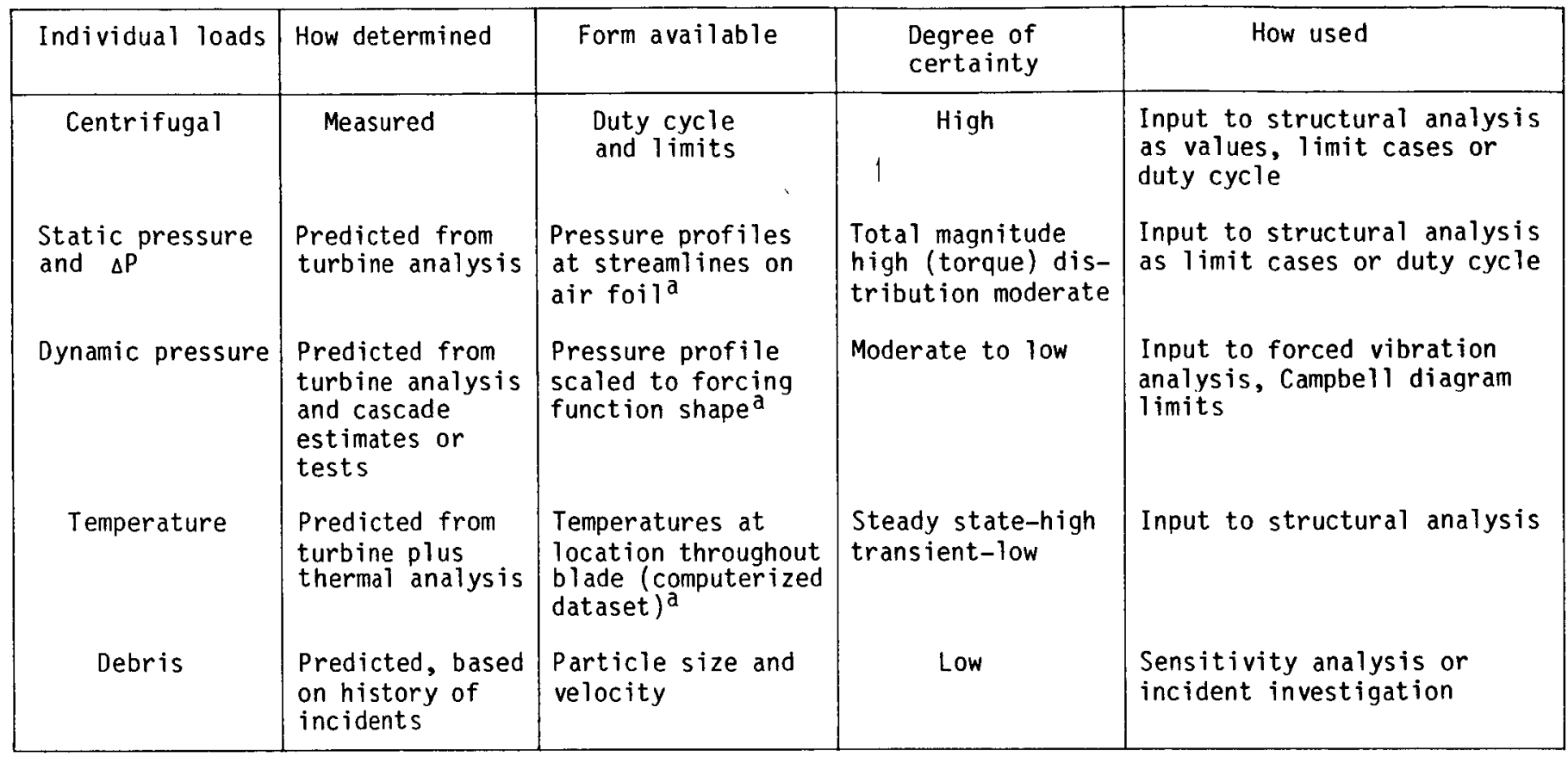

L Low frequency and transient

TABLE 2. - SUMMARY MATRIX OF INDIVIDUAL LOAD VERSUS COMPONENT

\begin{tabular}{|c|c|c|c|c|c|}
\hline Individual load & $\begin{array}{c}\text { Turbine } \\
\text { blade }\end{array}$ & $\begin{array}{c}\text { Transfer } \\
\text { duct }\end{array}$ & $\begin{array}{l}\text { Lox } \\
\text { post }\end{array}$ & HPOTPDD & Load form \\
\hline $\begin{array}{l}\text { Static pressure } \\
\text { Dynamic pressure } \\
\text { Chugging (transient) } \\
\text { Tubulence } \\
\text { Sinusidal } \\
\text { (repeated pulse) } \\
\text { Random } \\
\text { Centrifugal } \\
\text { Temperature } \\
\text { Structural vibration } \\
\text { Transient } \\
\text { Sideload } \\
\text { Pops } \\
\text { Steady state } \\
\text { Sine } \\
\text { Random } \\
\text { Debris } \\
\text { Rubbing } \\
\text { Installation } \\
\text { Fab } \\
\text { Friction } \\
\text { Tolerances }\end{array}$ & $\begin{array}{l}- \\
- \\
- \\
\bar{x} \\
\bar{x} \\
\bar{x} \\
\bar{x} \\
\bar{x}\end{array}$ & $\begin{array}{l}x \\
x \\
x \\
x \\
x \\
- \\
\bar{x} \\
x \\
x\end{array}$ & $\begin{array}{l}x \\
x \\
x \\
x \\
x \\
- \\
\bar{x} \\
x \\
x \\
x\end{array}$ & $\begin{array}{l}- \\
- \\
x \\
x \\
- \\
\bar{x} \\
x \\
\bar{x}\end{array}$ & $\begin{array}{l}\text { Duty cycle } \\
\text { AMS. statos } \\
\text { AMS. PSD. statos } \\
\text { AMS. PSD. } \\
\text { Duty cycle } \\
\text { Duty cycle } \\
\\
\text { AMS. statos } \\
\text { AMS. statos } \\
\text { AMS. PSD. statos } \\
\text { AMS. statos } \\
\text { History } \\
\text { Expert opinion } \\
\text { Expert opinion } \\
\text { PSEUDO load }\end{array}$ \\
\hline
\end{tabular}

a Low frequency and transient 


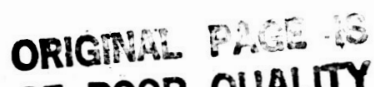 \\ OF. POOR QUALITY}

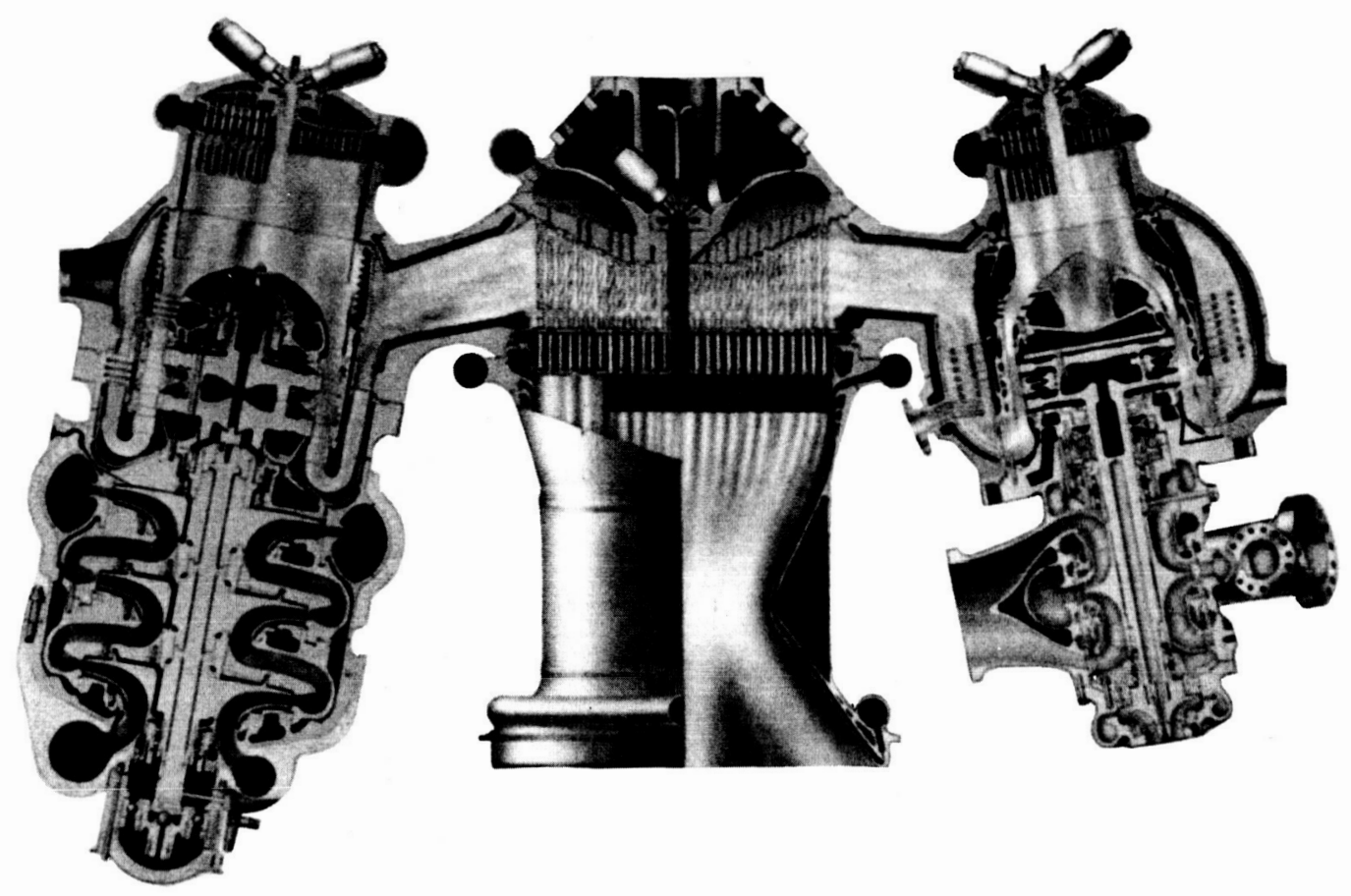

SSME POWERHEAD COMPONENT ARRANGEMENT.

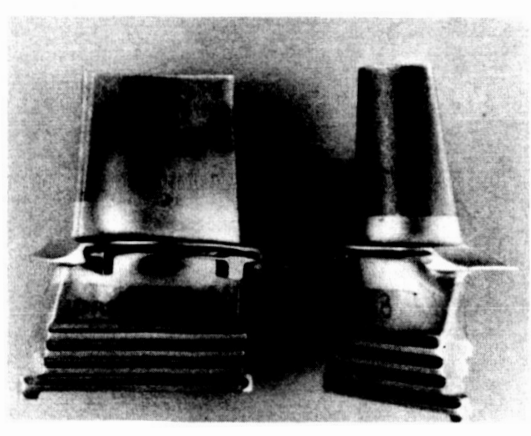

HIGH PRESSURE TURBOPUMP BLADE

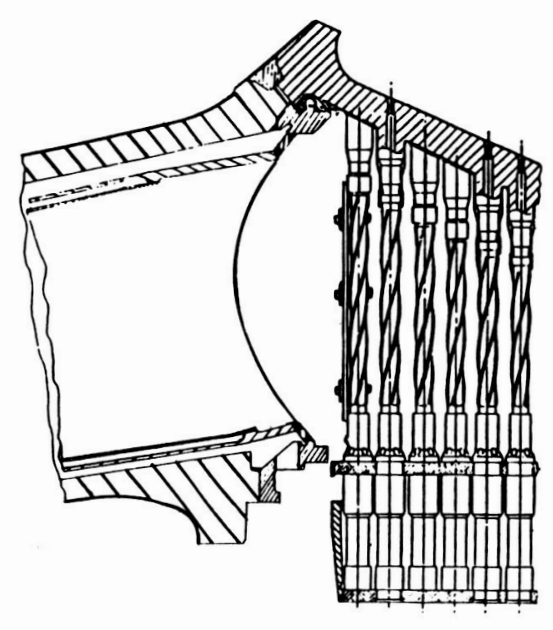

LOX POSTS

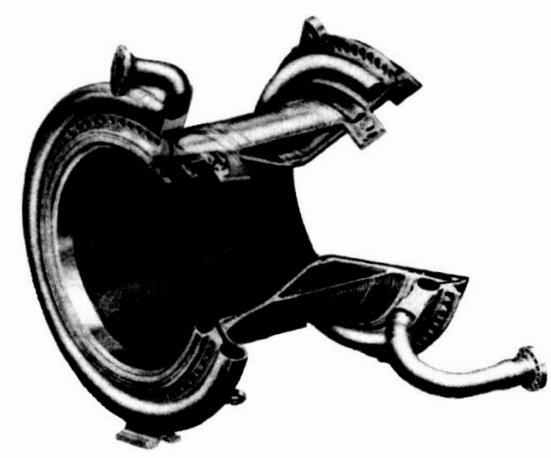

MAIN COMBUSTION CHAMBER

FiguRE 1. - PSAM WILL BE INITIALLY DEVELOPED FOR SELECT SSME STRUCTURAL COMPONENTS. 


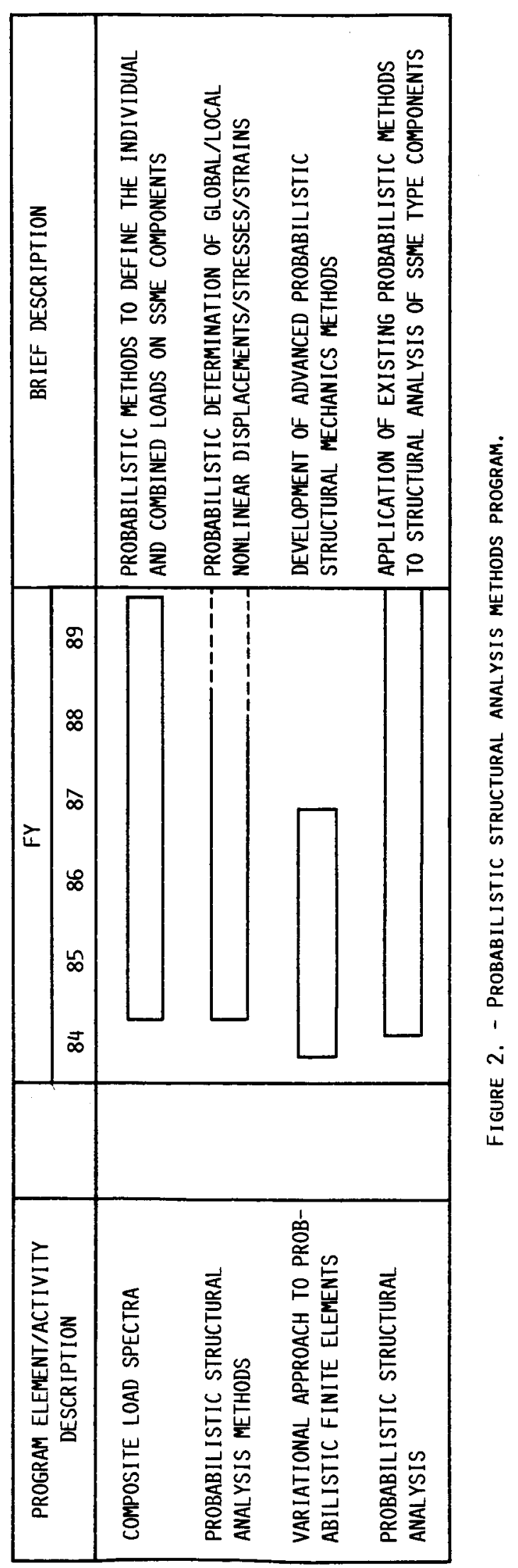




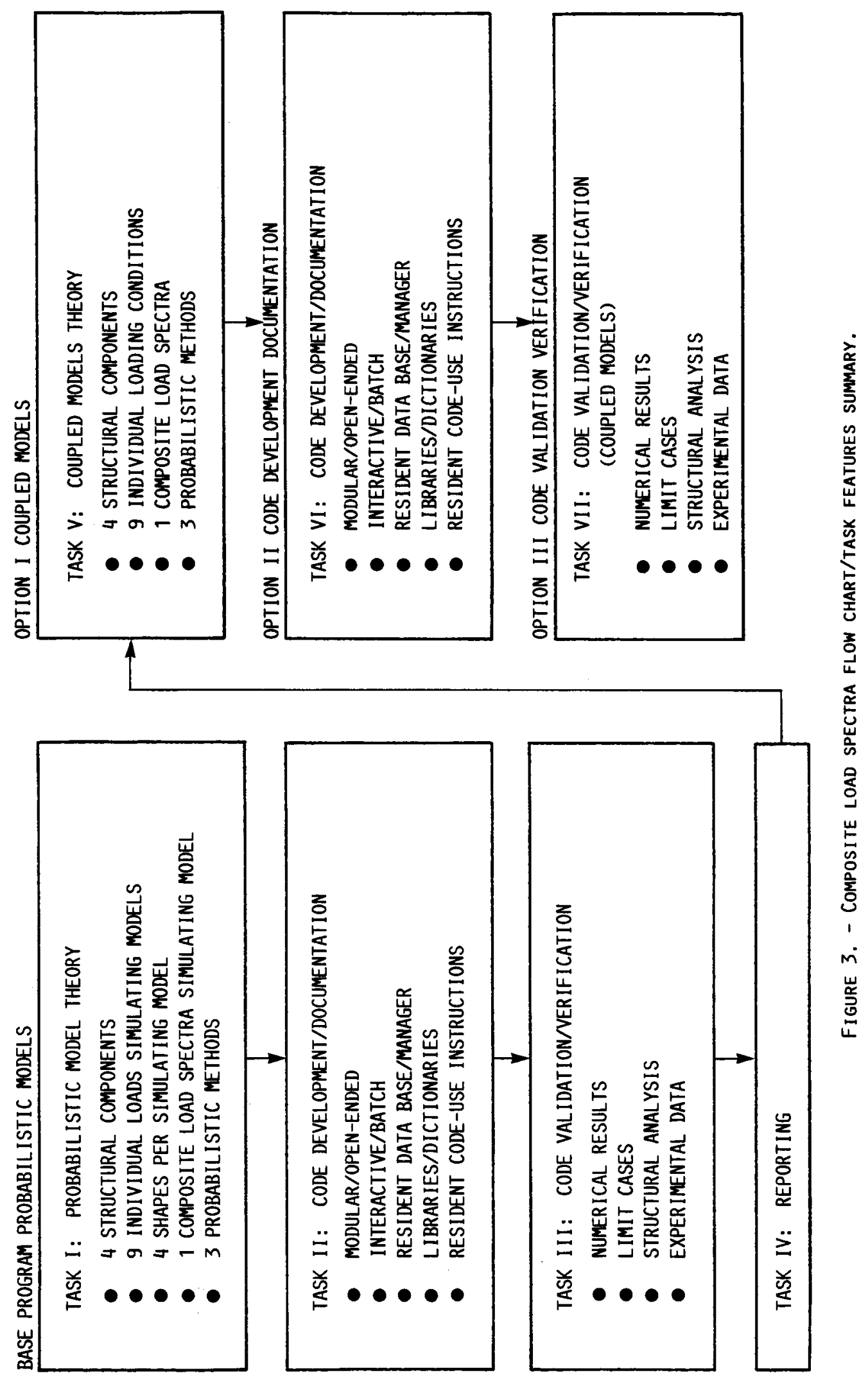




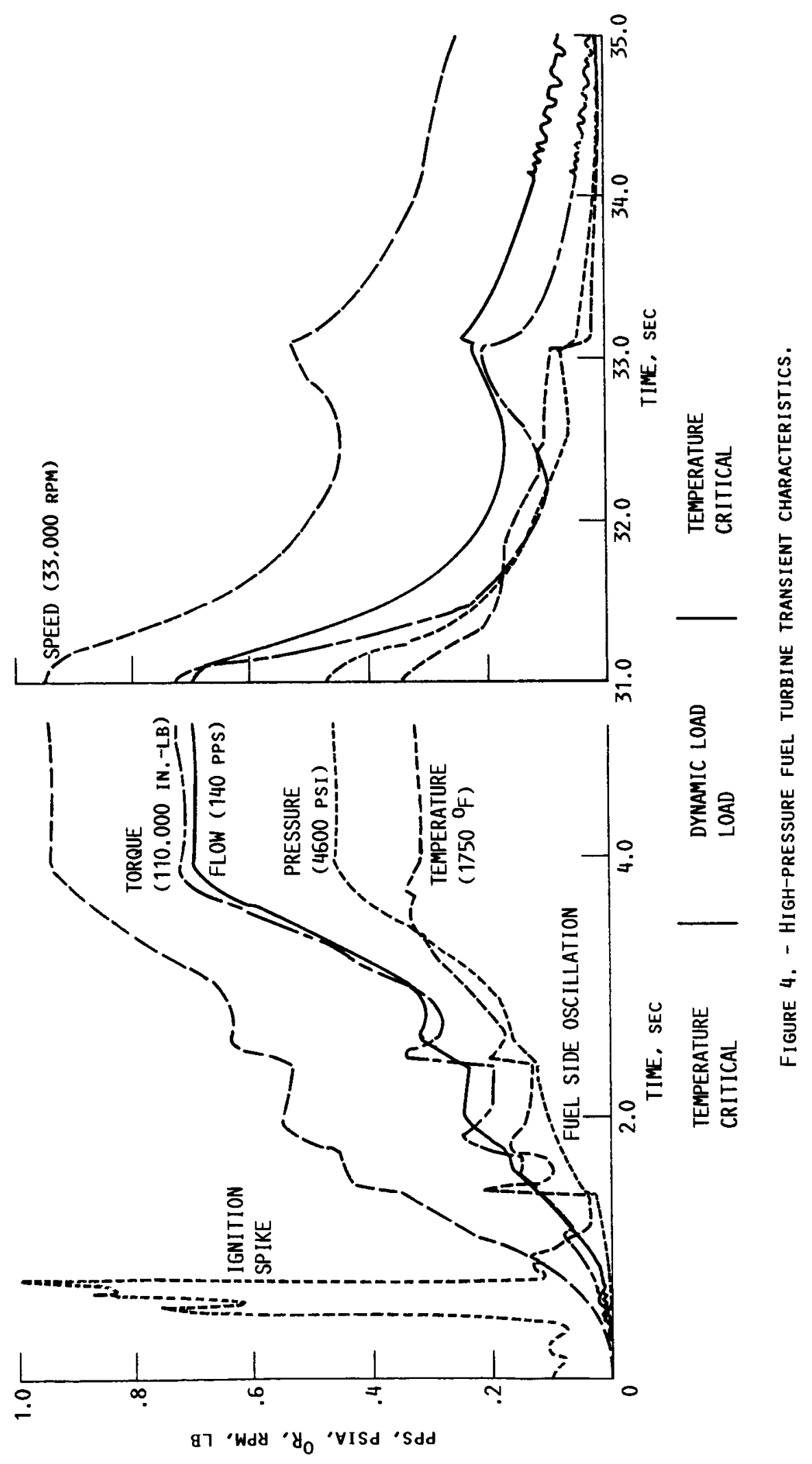




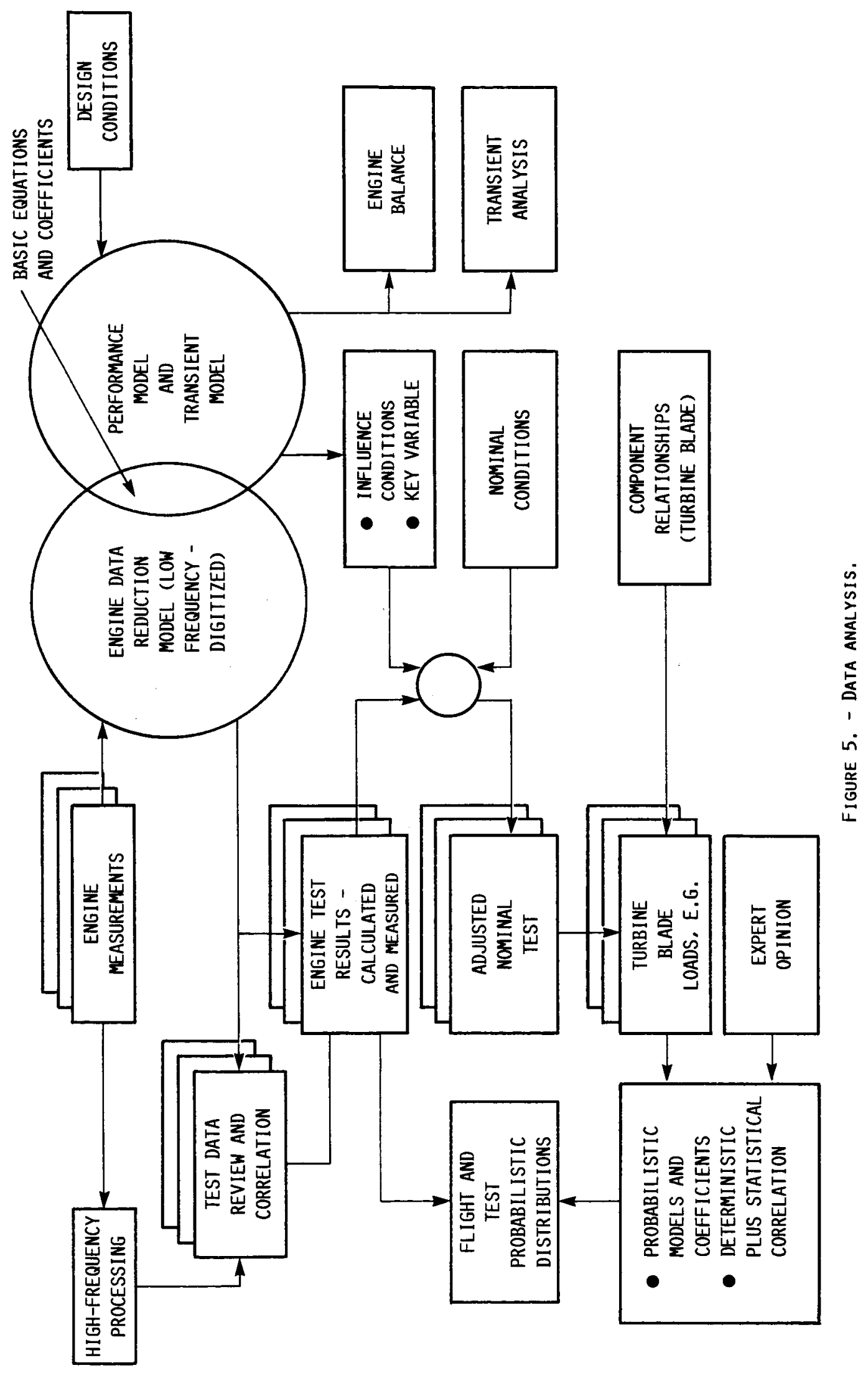




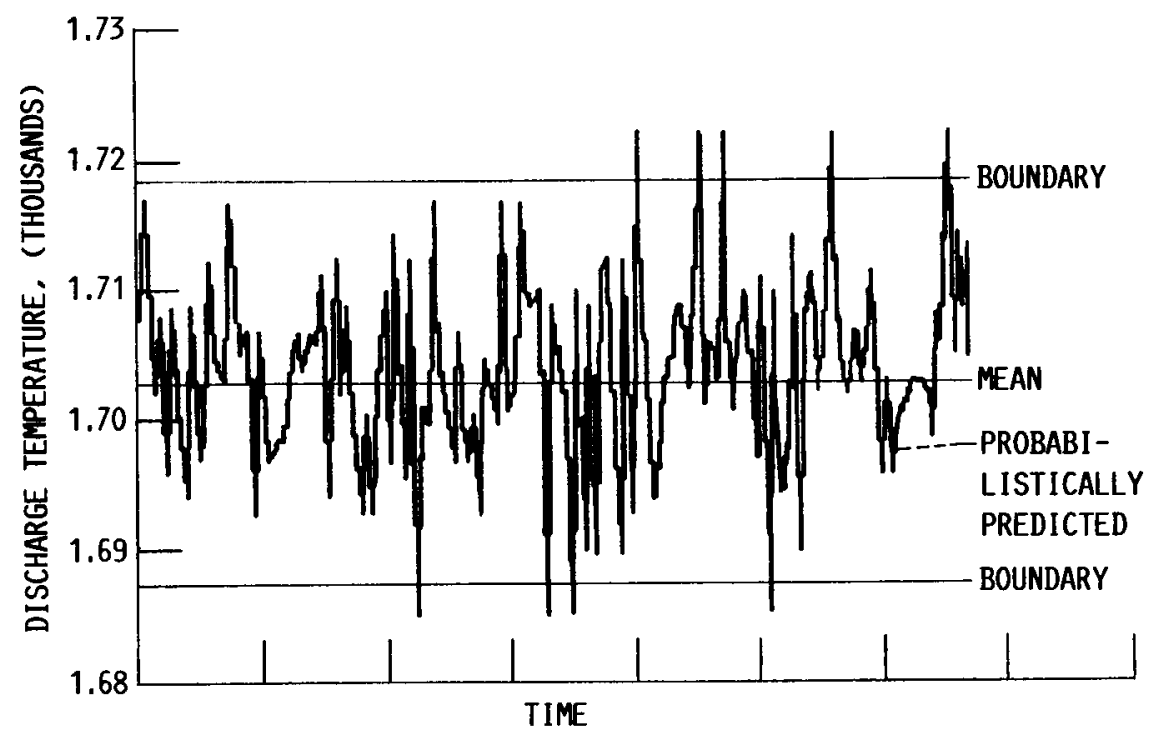

Figure 6. - hPFTP distance temperature. 
1. EXPERT SYSTEM

2. DATA ANALYSIS - STANDARD DISTRIBUTIONS AND DISCRETE DISTRIBUTIONS

3. PROBABILISTIC MODEL

- individual loadS

- compOSITE LOADS

4. INDIVIDUAL LOAD SHAPE SIMULATIONS

5. VARIOUS FORMS OF THE LOAD -

A. DUTY CYCLE

- SLOWLY VARYing

- rapidLy varying tRansients

B. SHOCK

C. VIBRATION

- STEADY STATE

- PSD, AMS

- SINUSOIDAL - PSD, ISOPLOT

- tRANSIENT

D. INFREQUENT LOADS

- DEBRIS

- RUBBING

6. GENERIC LOADS

- Definition

- implementation In EXPERT SYSTEm

- scaling techniques

7. VALIDATION AND VERIFICATION

8. ADDITIONAL COMPONENT

- tRANSFER DUCTS

- loX pOSt

- 4th COMPONENT

Figure 7. - KEY teCHNicAL fEATURES OF COMPOSITE LOAD CODE. 
LDEXPT DESIGN

COMPOSITE LOAD SPECTRA EXPERT SYSTEM

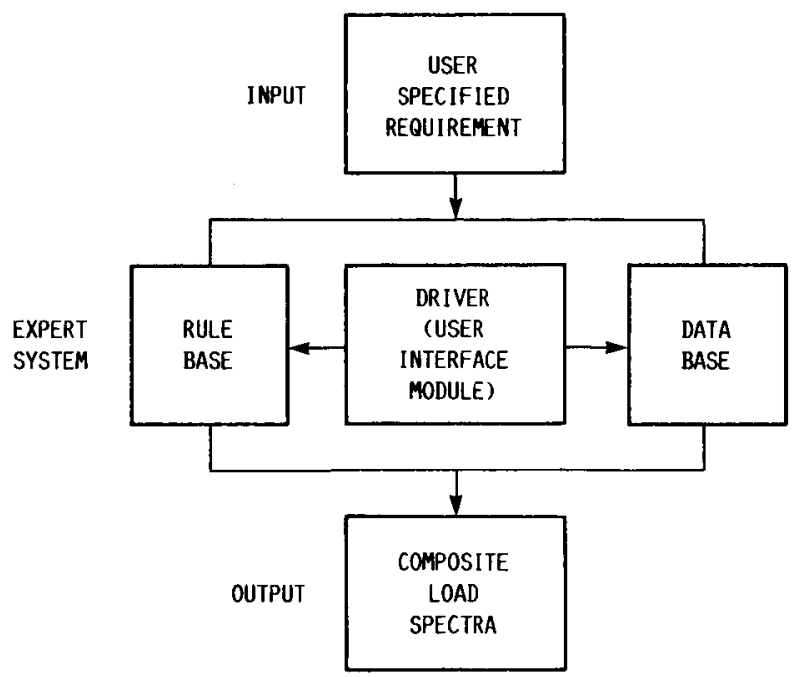

LOAD EXPERT SYSTEM DESIGN PHILOSOPHY

- RULE-BASE PRODUCTON SYSTEM

- IF THEN RULES

- SIMPLE INFERENCE SCHEME

- INFERENCE NET (DECISION TREE)

- SOPHISTICATED PROBABILISTIC MeThODS

- disCRETE PROBABILITY DISTRIBUTION

- honte carlo

- barrier crossing

- POWERFUL KNONLEDGE BASE

- INFLUENCE COEFFICIENT

- scaling coefFicients

- DUTY CYCLE LOAD PROFILES

- engine configuration and geonetry data

- raw engine flight and test data

FiguRE 8. - COMPOSITE LOAD SPECTRA SIMULATION USING EXPERT SYSTEMS.

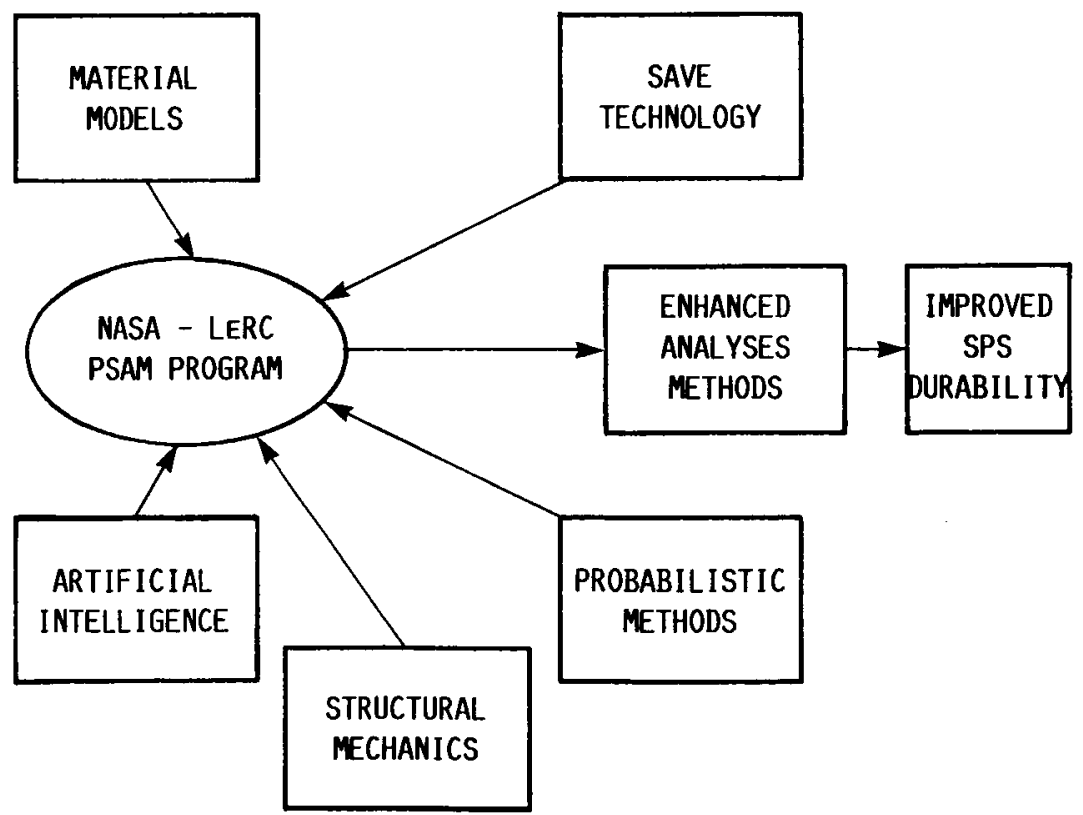

FiguRE 9. - PSAM INTEGRATES EXISTING TECHNOLOgIES. 


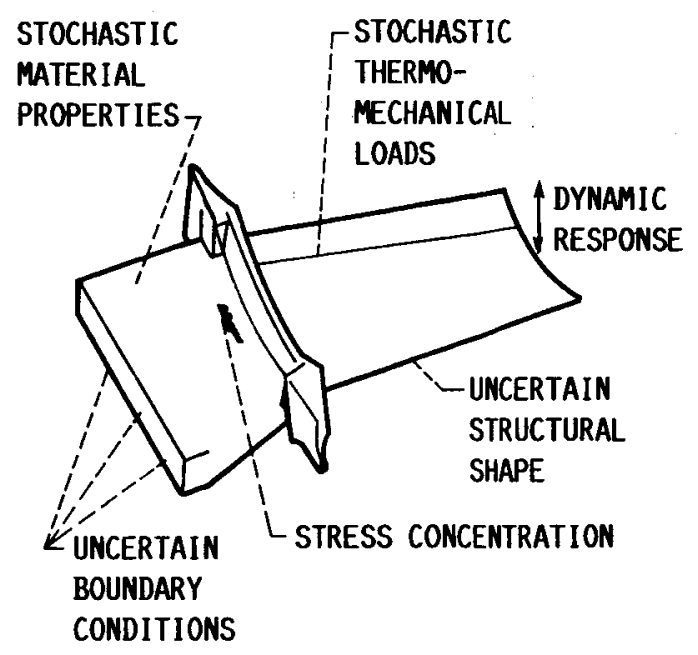

THE PROBABILISTIC STRUCTURAL ANALYSIS PROBLEM
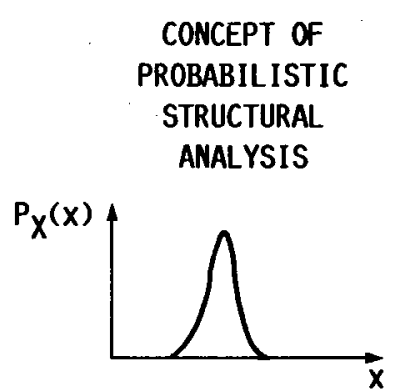

INPUT PDF

(LOAD, MATERIAL, GEOMETRY, BOUNDARY CONDITIONS)

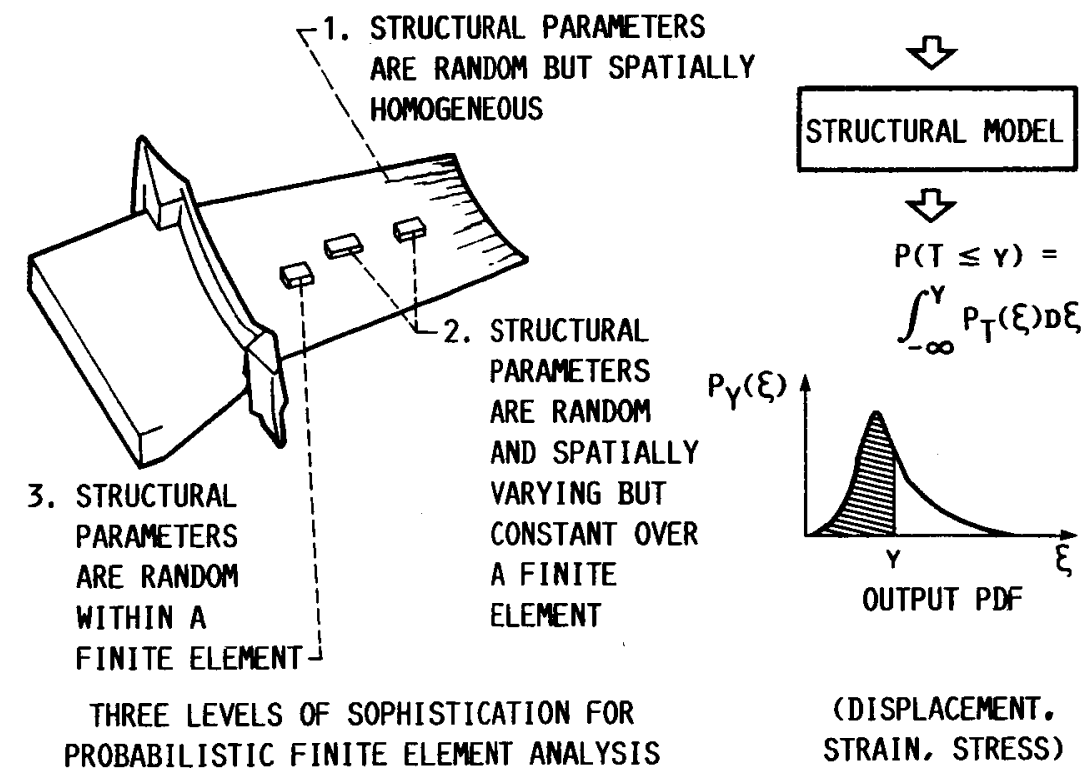

Figure 10. - Probabilistic structural analysis definition. 

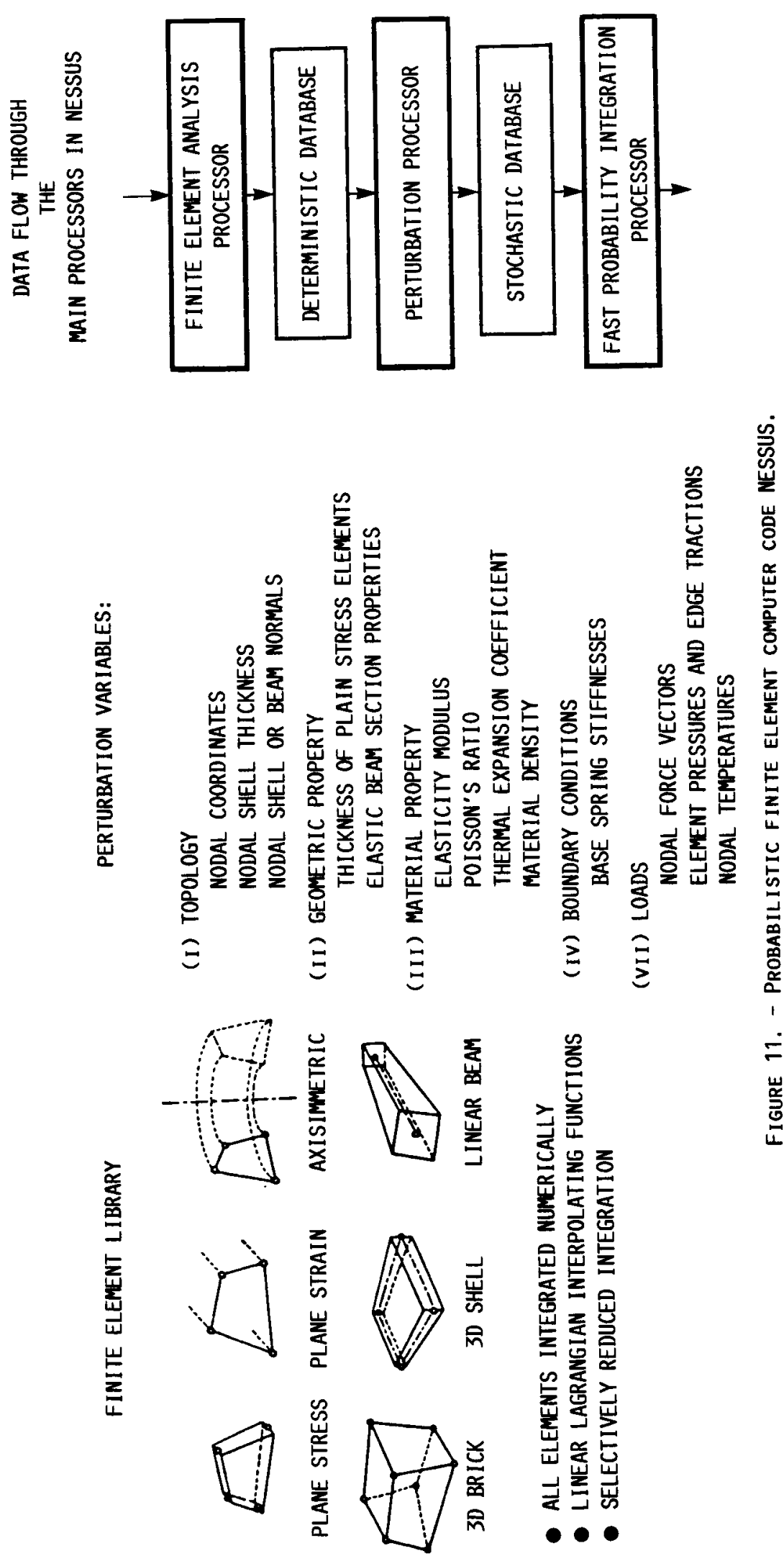

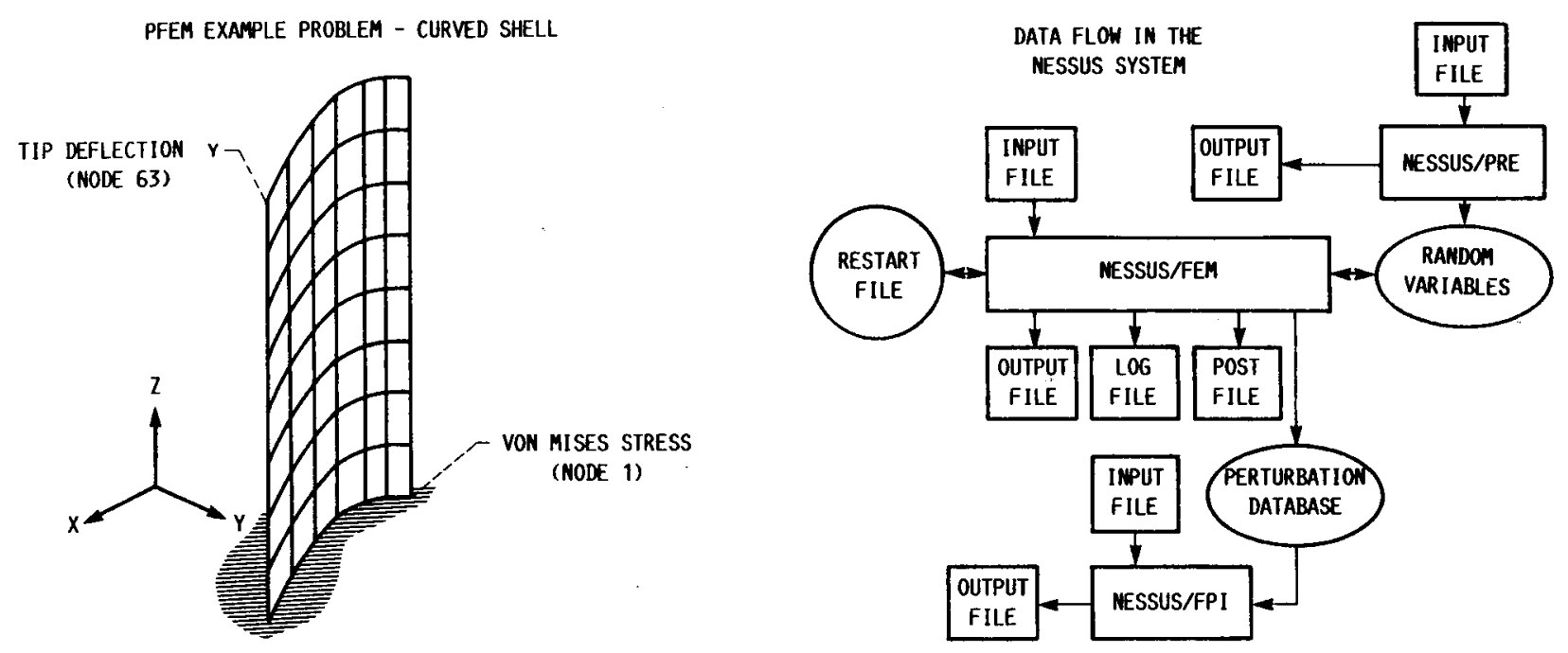

RANDOM VARIABLES FOR CURVED SHELL

EXAMPLE PROBLEM

\begin{tabular}{|c|c|c|c|c|}
\hline RANDOM VARIABLE & MEAN & $\begin{array}{l}\text { COEFFICIENT OF } \\
\text { VARIATION (COV) }\end{array}$ & DISTR IBUTION & INDEPENDENT \\
\hline SHELL THICKNESS & $0.15 \mathrm{IN}$. & 0.05 & LOGNORMAL & YES \\
\hline $\begin{array}{l}\text { BASE STIFFNESS } \\
\text { FACTOR }\end{array}$ & 1.0 & 0.20 & EXTREME VALUE & YES \\
\hline TEMPERATURE & $1000^{\circ} \mathrm{F}$ & 0.05 & NORMAL & No \\
\hline PRESSURE & 100 PSI & 0.10 & NORMAL & NO \\
\hline $\begin{array}{l}\text { MATERIAL YIELD } \\
\text { STRENGTH }\end{array}$ & $180 \mathrm{kSI}$ & 0.05 & NORMAL & YES \\
\hline
\end{tabular}

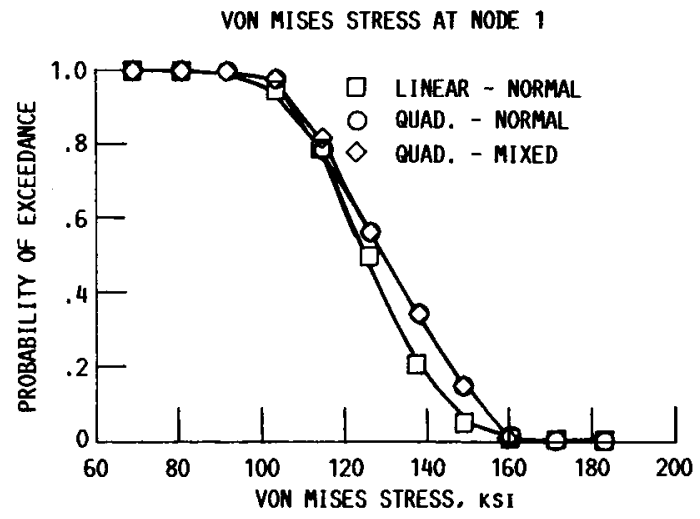

Figure 12. - Probabilistic finite element stress analysis. 

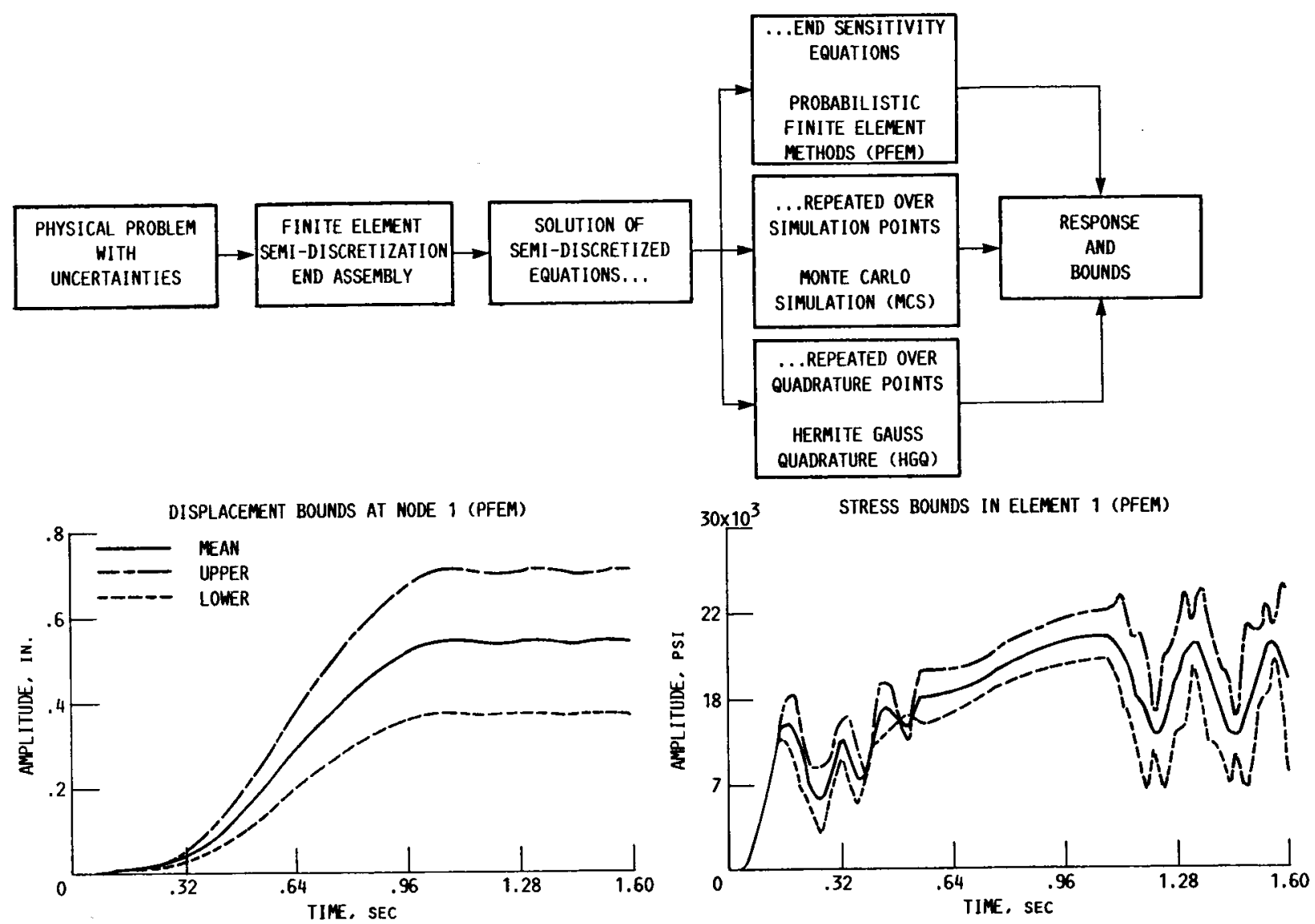

FigURE ]3, - VARIATIONAL APPROACH TO PROBABILISTIC FINITE ELEMENTS. 


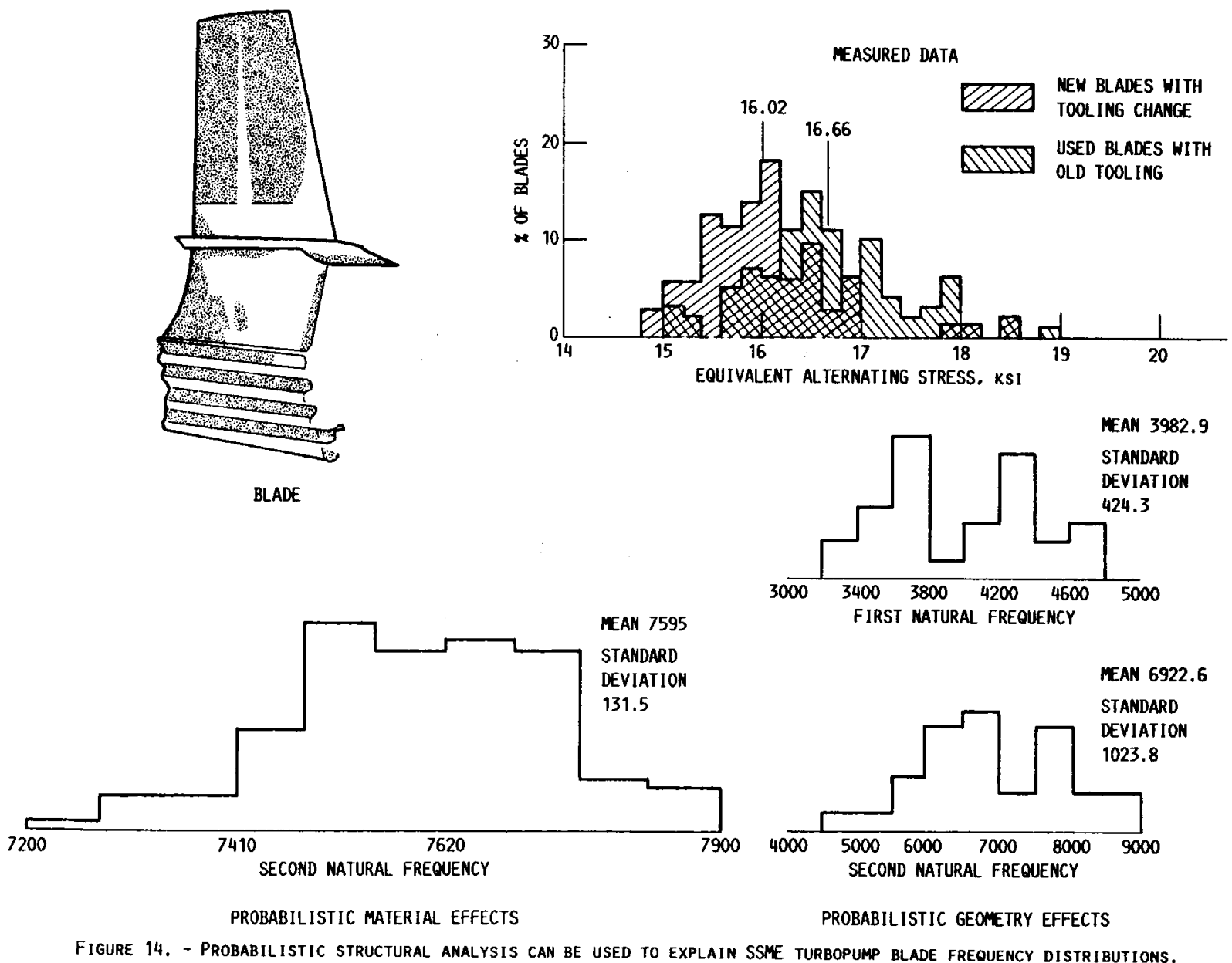




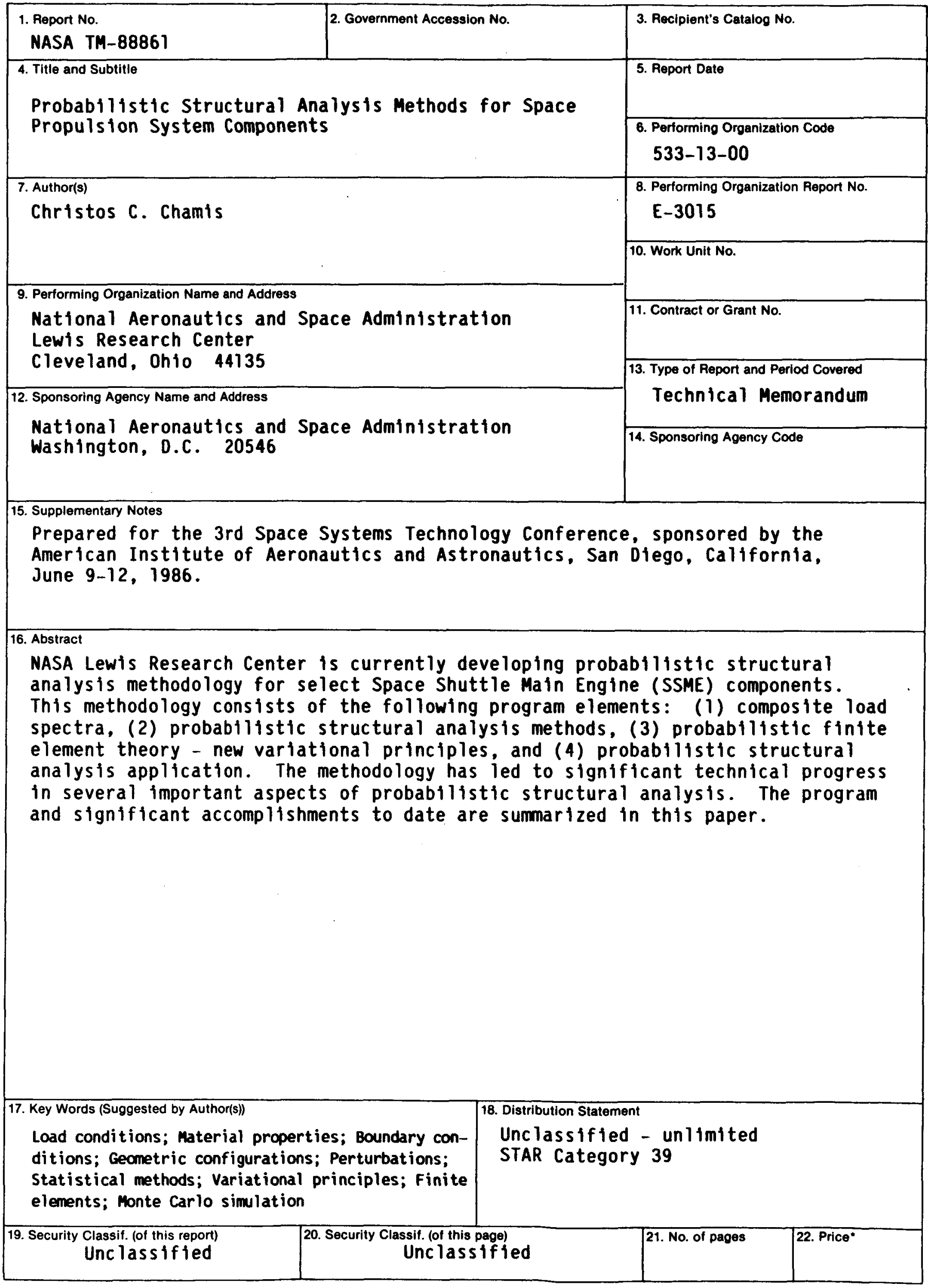

"For sale by the National Technical Information Service, Springfield, Virginia 22161 